\title{
Bacteriophages isolated from dairy farm mitigated Klebsiella pneumoniae-induced inflammation in bovine mammary epithelial cells cultured in vitro
}

Yuxiang Shi ${ }^{1,2+}$, Wenpeng Zhao ${ }^{1 \dagger}$, Gang Liu ${ }^{1}$, Tariq Ali ${ }^{1,3}$, Peng Chen ${ }^{1}$, Yongxia Liu ${ }^{4}$, John P. Kastelic ${ }^{5}$, Bo $\operatorname{Han}^{1 *}$ (D) and Jian Gao ${ }^{1 *}$

\begin{abstract}
Background: Klebsiella pneumoniae, an environmental pathogen causing mastitis in dairy cattle, is often resistant to antibiotics. K. pneumoniae was used as the host bacteria to support bacteriophage replication; 2 bacteriophages, CM8-1 and SJT-2 were isolated and considered to have therapeutic potential. In the present study, we determined the ability of these 2 bacteriophages to mitigate cytotoxicity, pathomorphological changes, inflammatory responses and apoptosis induced by K. pneumoniae (bacteriophage to K. pneumoniae $\mathrm{MOI}$ 1:10) in bovine mammary epithelial cells (bMECs) cultured in vitro.

Results: Bacteriophages reduced bacterial adhesion and invasion and cytotoxicity (lactate dehydrogenase release). Morphological changes in bMECs, including swelling, shrinkage, necrosis and hematoxylin and eosin staining of cytoplasm, were apparent 4 to $8 \mathrm{~h}$ after infection with K. pneumoniae, but each bacteriophage significantly suppressed damage and decreased TNF- $a$ and IL-1 $\beta$ concentrations. K. pneumoniae enhanced mRNA expression of TLR4, NF-KB, TNF-a, IL-1 $\beta, I L-6, I L-8$, caspase-3, caspase-9 and cyt-c in bMECs and increased apoptosis of bMECs, although these effects were mitigated by treatment with either bacteriophage for $8 \mathrm{~h}$.

Conclusions: Bacteriophages CM8-1 and SJT-2 mitigated K. pneumoniae-induced inflammation in bMECs cultured in vitro. Therefore, the potential of these bacteriophages for treating mastitis in cows should be determined in clinical trials.
\end{abstract}

Keywords: Klebsiella pneumoniae, Bovine mastitis, Bacteriophage, Inflammation, Apoptosis, bMECs

\section{Background}

Bovine mastitis caused by infection with pathogenic microorganisms reduces milk production and quality, inflicting huge economic losses in the dairy industry $[1,2]$. Klebsiella pneumoniae, a common environmental pathogen, causes mastitis in dairy cows [3, 4],

\footnotetext{
*Correspondence: hanbo@cau.edu.cn; gaojian2016@cau.edu.cn

${ }^{\dagger}$ Yuxiang Shi and Wenpeng Zhao contributed equally to this work.

${ }^{1}$ College of Veterinary Medicine, China Agricultural University, Yuan Ming

Yuan West Road No. 2, Haidian District, 100193 Beijing, P. R. China

Full list of author information is available at the end of the article
}

accounting for 10 to $13 \%$ clinical mastitis, second to E. coli $[5,6]$. Although antimicrobials are the most common therapy for bovine mastitis caused by $K$. pneumoniae, it often has single or multidrug resistance [4], with increasing risk of recurrence after treatment.

Bovine mammary epithelial cells (bMECs) are the first line of defense against invading pathogens that enter the udder through the streak canal, at the distal end of the bovine teat $[4,7]$. Thus, bMECs have critical roles in

(c) The Author(s). 2021 Open Access This article is licensed under a Creative Commons Attribution 4.0 International License, which permits use, sharing, adaptation, distribution and reproduction in any medium or format, as long as you give appropriate credit to the original author(s) and the source, provide a link to the Creative Commons licence, and indicate if changes were made. The images or other third party material in this article are included in the article's Creative Commons licence, unless indicated otherwise in a credit line to the material. If material is not included in the article's Creative Commons licence and your intended use is not permitted by statutory regulation or exceeds the permitted use, you will need to obtain permission directly from the copyright holder. To view a copy of this licence, visit http://creativecommons.org/licenses/by/4.0/ The Creative Commons Public Domain Dedication waiver (http://creativecommons.org/publicdomain/zero/1.0/) applies to the data made available in this article, unless otherwise stated in a credit line to the data. 
both nonspecific and specific immune defenses against infection by pathogenic microorganisms [7]; furthermore, they can be infected by a variety of pathogenic microorganisms that damage these cells, leading to mastitis $[8,9]$. Toll-like Receptor 4 (TLR4) and the NF- $k B$ pathway are classic regulators of inflammation [10]. Lipopolysaccharides (LPS), the main component of the cell wall of gram-negative bacteria, can activate the TLR4mediated NF- $\mathrm{kB}$ pathway to induce an inflammatory response [11]. Inhibiting or knocking out TLR4 downregulated expression of inflammatory factors in cells, thereby suppressing inflammation [11, 12]. Although a timely and appropriate inflammatory response can effectively contain invading pathogens, an excessive inflammatory response can cause various degrees of cellular damage, including apoptosis, necrosis or pyroptosis $[13,14]$. K. pneumoniae can multiply rapidly in bovine mammary tissues, causing a severe inflammatory response and tissue damage $[4,15]$. In bovine mastitis induced by $K$. pneumoniae, infection of bMECs is an important component. Antibiotics are commonly used to treat bovine mastitis and consequently, drug resistance in gram-negative bacteria, including K. pneumoniae, is rapidly increasing $[3,16,17]$. Therefore, it is important to identify alternatives to antibiotics for treating bacterial infections, especially for bovine mastitis caused by $K$. pneumoniae.

Bacteriophages are small viruses, nearly ubiquitous in the natural environment [18]. Bacteriophage can lyse pathogens in vivo and in vitro without harmful effects on host cells and have been widely used in various fields $[19,20]$. For example, 3 Myoviridae bacteriophages were used as adjunctive therapy and were safe and effective with severe Staphylococcus aureus infections [21]. Furthermore, a bacteriophage "cocktail" was very successful in controlling bacterial wilt in tomatoes [22]. However, use of a bacteriophage for treatment of bovine mastitis caused by $K$. pneumoniae has apparently not been reported. Therefore, our objective was to investigate the role of bacteriophages for controlling K. pneumoniae in an in vitro infection model of bMECs.

\section{Results}

\section{Transmission electron microscopy (TEM) of bacteriophages}

Ultrastructures of $K$. pneumoniae bacteriophages CM8-1 and SJT-2 are shown (Fig. 1). Bacteriophages CM8-1 and SJT-2 were comprised of a head, neck and tail wire (Fig. 1A2, B2). Bacteriophages CM8-1 and SJT-2 had a polyhedral head, approximately 100 and $103 \mathrm{~nm}$, respectively, whereas their tails were 103 and $116 \mathrm{~nm}$ and contained obvious tail filaments (Fig. 1A2, B2).

\section{Effect of bacteriophages on adhesion and invasion of $K$. pneumoniae}

Adhesion of $K$. pneumoniae to bMECs in the K. pneumoniae, K. pneumoniae + CM8-1 and K. pneumoniae + SJT-2

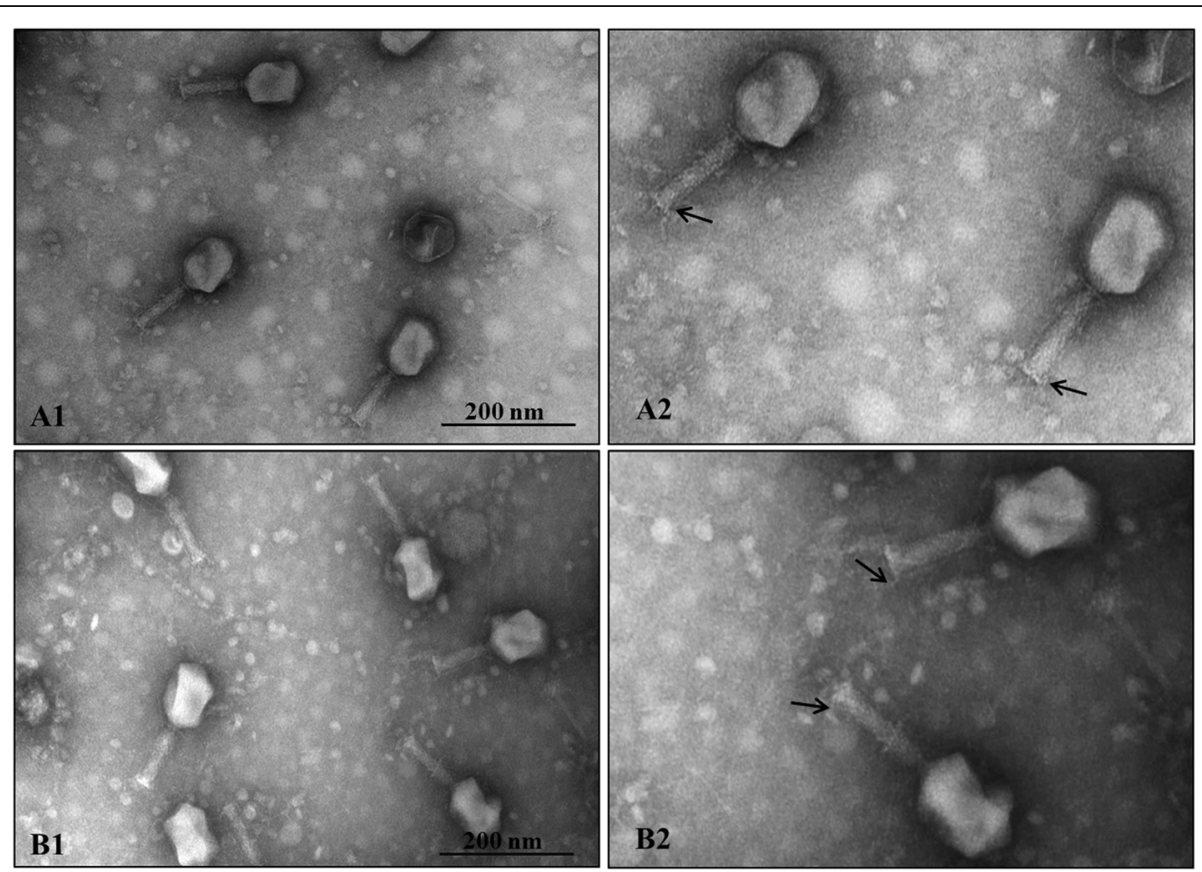

Fig. 1 Transmission electron micrographs of Klebsiella pneumoniae bacteriophages CM8-1 and SJT-2. A1 and A2 are the ultrastructure of phage CM8-1, whereas B1 and B2 are the ultrastructure of phage SJT-2. Black arrows indicate tail filaments 
groups were significantly increased in comparison to the Control (Fig. 2a). Starting soon after K. pneumoniae infection and as interval after infection increased, bacteriophages CM8-1 and SJT-2 reduced adhesion $(P<0.01)$ of $K$. pneumoniae to bMECs in the K. pneumoniae + CM8-1 and K. pneumoniae + SJT-2 groups as compared to the $K$. pneumoniae group at 1.5, 2, 2.5 and $3 \mathrm{~h}$ post infection (hpi) (Fig. 2a).

Adhesion of $K$. pneumoniae to bMECs in the K. pneumoniae + CM8-1 and K. pneumoniae + SJT-2 groups was similar to that in the K. pneumoniae group, without significant changes at $0.5 \mathrm{hpi}$ (Fig. 2B). However, as duration of infection increased, adhesion of $K$. pneumoniae to bMECs in the K. pneumoniae, K. pneumoniae + CM8-1 and $K$. pneumoniae $+\mathrm{SJT}-2$ groups increased $(P<0.01)$ compared to the Control group (Fig. 2B). Furthermore, adhesion of $K$. pneumoniae to bMECs in the K. pneumoniae + CM8-1 and K. pneumoniae + SJT-2 groups was lower $(P<0.01)$ than that of the $K$. pneumoniae group at 2, 2.5 and 3 hpi (Fig. 2B).

\section{Effect of bacteriophages on K. pneumoniae-induced cytotoxicity in bMECs}

There was no difference in $\mathrm{LDH}$ release among the Control, CM8-1 and SJT-2 groups (Fig. 3). At 2 hpi with $K$. pneumoniae, $\mathrm{LDH}$ release in the $K$ pneumoniae group was higher $(P<0.01)$ than in the Control group (Fig. 3), whereas at 4, 6 and $8 \mathrm{hpi}, \mathrm{LDH}$ release in the $K$. pneumoniae, K. pneumoniae + CM8-1 and K. pneumoniae + SJT-2 groups was greater $(P<0.01)$ than in the Control group (Fig. 3). At 2, 4, 6 and 8 hpi, LDH release in the $K$. pneumoniae + CM8-1 and K. pneumoniae+ SJT-2 groups was significantly decreased compared to the $K$. pneumoniae group (Fig. 3 ).

\section{Morphological changes in bMECs}

At 2 hpi with $K$. pneumoniae, morphological appearance was similar in the $K$. pneumoniae and Control groups. At 4 and $6 \mathrm{hpi}$ with $K$. pneumoniae, there was no significant changes compared to the Control group (Fig. 4A1-C1, A2-C2). However, at 8 hpi with $K$. pneumoniae, damage to bMECs in $K$. pneumoniae group included cell swelling, nuclear hyperchromatism and necrosis, as well as reductions in number of bMECs, compared to the Control group (Fig. 4D1D2). Furthermore, the extent of damage to bMECs gradually increased with interval after infection. However, morphology of bMECs in the $K$. pneumoniae+ CM8-1 and K. pneumoniae + SJT-2 groups was similar compared to the $K$. pneumoniae and Control groups at 2 hpi. Swelling and necrosis of bMECs in the $K$.

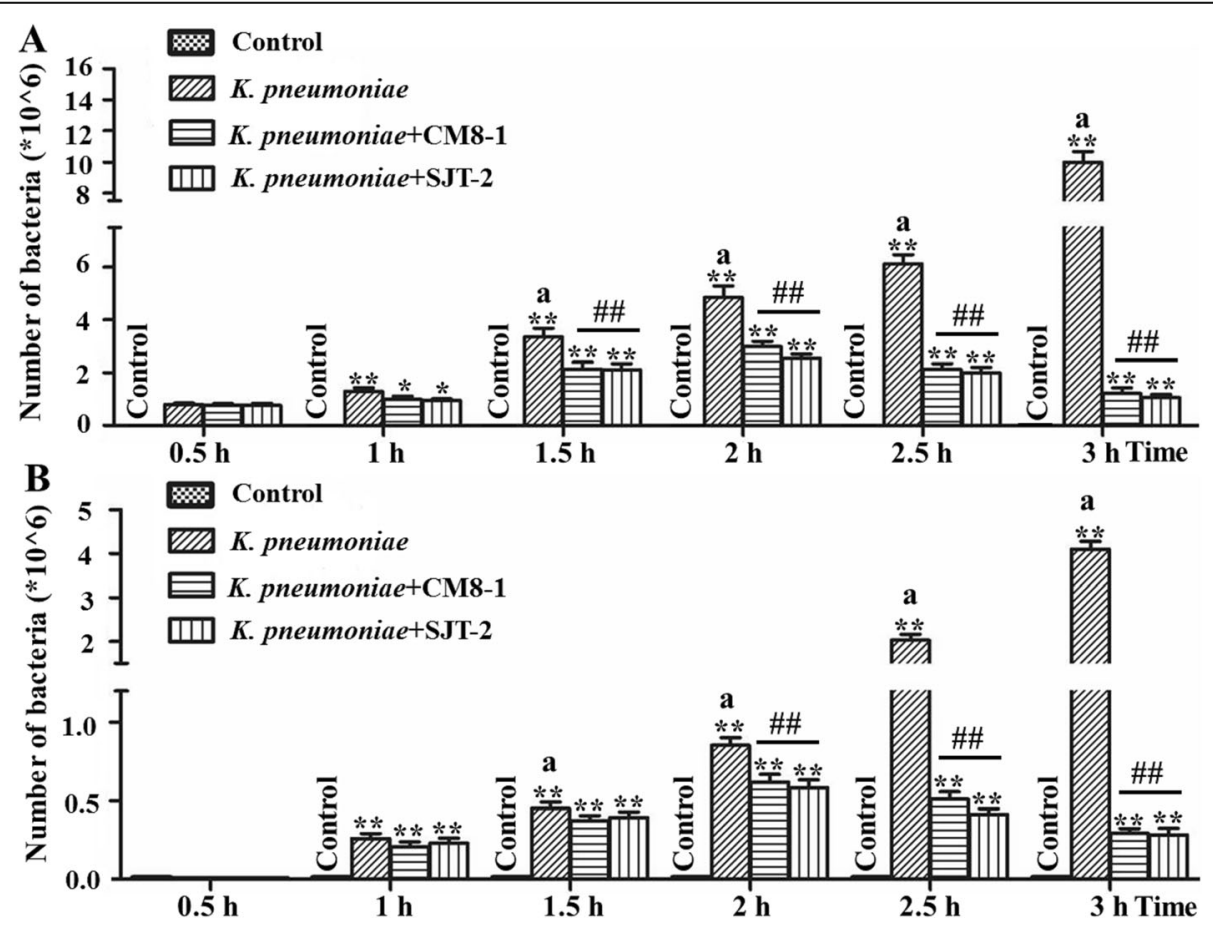

Fig. 2 Adhesion and invasion of Klebsiella pneumoniae-infected bovine mammary epithelial cells in presence of bacteriophages CM8-1 or SJT-2. a Adhesion of $K$. pneumoniae to bMECs, $\mathbf{b}$ Invasion of $K$. pneumoniae into bMECs. Compared to the previous time point in the same group: ${ }^{a} P<$ 0.01; compared to the Control group: ${ }^{*} P<0.05,{ }^{*} P<0.01$; compared to the $K$. pneumoniae group: ${ }^{\#} P<0.05$, ${ }^{\# \#} P<0.01$ 


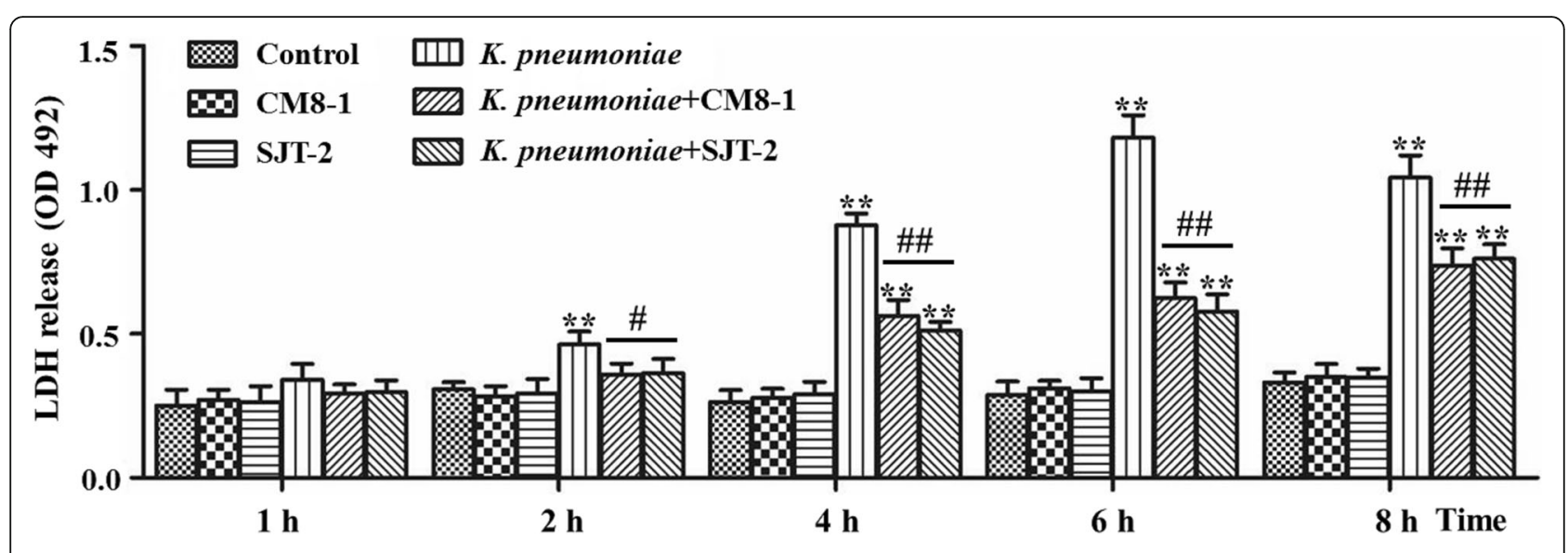

Fig. $\mathbf{3}$ Lactate dehydrogenase $(\mathrm{LDH})$ release from Klebsiella pneumoniae-infected bovine mammary epithelial cells in presence of bacteriophages CM8-1 or SJT-2. Compared to the Control group: ${ }^{*} P<0.05,{ }^{* *} P<0.01$; compared to the K. pneumoniae group: ${ }^{\#} P<0.05,{ }^{\# \#} P<0.01$

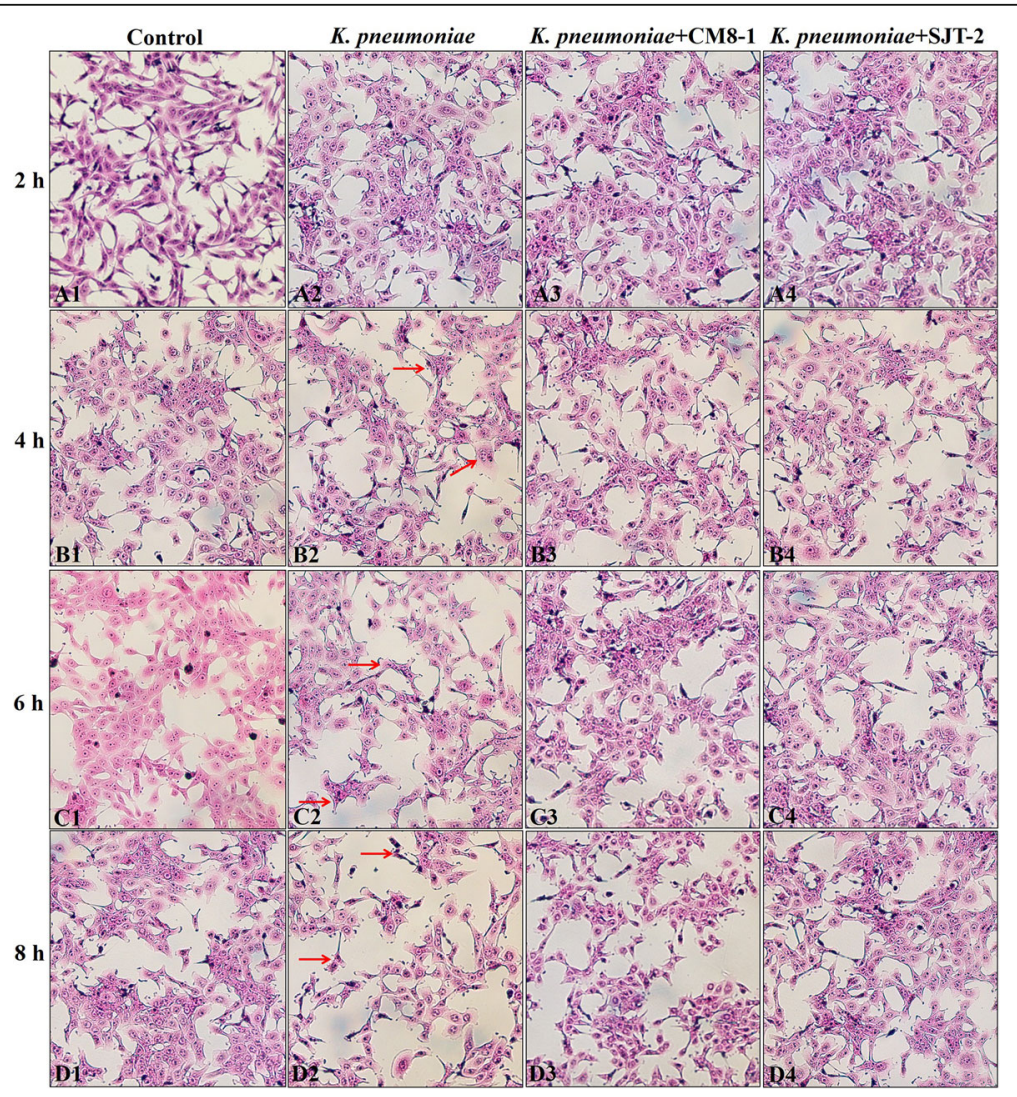

Fig. 4 Morphological observations (40X) of Klebsiella pneumoniae-infected bMECs in presence of bacteriophages CM8-1 or SJT-2. A1-D1: Normal bMECs in the Control group at 2, 4, 6 and 8 h. A2-D2: Note damage to bMECs, including necrosis and swelling, shrinkage, loss of cell integrity, necrosis and heavy staining, and reductions in cell number at 2, 4,6 and $8 \mathrm{~h}$ after infection in K. pneumoniae group. A3-D3 and A4-D4: Phages CM8-1 and SJT-2 mitigated cell damage caused by K. pneumoniae infection at 2, 4, 6 and $8 \mathrm{~h}$ in the K. pneumoniae + CM8-1 and K. pneumoniae+ SJT-2 groups, respectively 
pneumoniae + CM8-1 and K. pneumoniae + SJT-2 groups were less severe compared to the $K$. pneumoniae group at 4, 6 and 8 hpi (Fig. 4A3-D3, A4-D4).

Effect of bacteriophages on concentrations of inflammatory factors and inflammatory responses in $K$. pneumoniae-infected bMECs

Concentrations of IL- $1 \beta$ and TNF- $\alpha$ proteins were increased $(P<0.01)$ at 4,6 and 8 hpi with $K$. pneumoniae (Fig. $5 \mathrm{a}$ and b). However, TNF- $\alpha$ and IL- $1 \beta$ concentrations in the $K$. pneumoniae + CM8-1 and $K$. pneumoniae +SJT-2 groups were significantly decreased in comparison to the $K$. pneumoniae group at 4, 6 and 8 hpi (Fig. 5a and b).

Expression levels of TLR4, NF-kB and inflammatory factors (TNF- $\alpha$, IL-1 $\beta$, IL- 6 and IL- 8 ) in bMECs were determined by real-time PCR. At $2 \mathrm{hpi}$, mRNA expression levels of TLR4, NF-kB, TNF- $\alpha$, IL-1 $\beta$, IL-6 and IL-8 in bMECs were significantly higher in the $K$. pneumoniae versus Control groups (Fig. 6a-f). Furthermore, at 4, 6 and $8 \mathrm{hpi}$, mRNA expression levels of TLR4, NF- $\mathrm{KB}$ and inflammatory factors in the $K$. pneumoniae, K. pneumoniae + CM8-1 and K. pneumoniae + SJT-2 groups were significantly up-regulated compared to the Control group (Fig. 6a-f). In contrast, after treatment with bacteriophages CM8-1 and SJT-2, at 4, 6 and 8 hpi, mRNA expression levels of TLR4, NF- $\mathrm{kB}$ and inflammatory factors in the $K$. pneumoniae + CM8-1 and $K$. pneumoniae + SJT-2 groups were significantly down-regulated as compared to the K. pneumoniae group (Fig. 6a-f).
Effect of bacteriophages on apoptosis in infected bMECs At 2 hpi of bMECs with $K$. pneumoniae, mRNA expression levels of apoptosis factors caspase- 3 and caspase-9 were higher $(P<0.05)$ in the $K$. pneumoniae groups than in the Control group (Fig. 7a, b). At 4, 6 and 8 hpi, mRNA expression levels of apoptosis factors in the $K$. pneumoniae, K. pneumoniae + CM8-1 and K. pneumoniae + SJT-2 groups were significantly up-regulated compared to Controls (Fig. 7a-c). When compared to the $K$. pneumoniae group, at 4, 6 and $8 \mathrm{hpi}$, bacteriophages CM8-1 and SJT-2 significantly down-regulated mRNA expression levels of apoptosis factors in the K. pneumoniae + CM8-1 and $K$. pneumoniae + SJT-2 groups (Fig. 7a-c).

Apoptosis of bMECs in the K. pneumoniae group was higher $(P<0.05)$ than in the Control group at $2 \mathrm{hpi}$ (Fig. 8). Furthermore, apoptosis rate of bMECs in the $K$. pneumoniae + CM8-1 and $K$. pneumoniae + SJT-2 groups was lower $(P<0.01)$ compared to the $K$. pneumoniae group at 4, 6 and 8 hpi (Fig. 8), although apoptosis was significantly higher in each of these groups compared to the Control group at all of these time points (Fig. 8).

\section{Discussion}

This was apparently the first report that bacteriophages CM8-1 and SJT-2 isolated from mastitic bovine milk mitigated inflammatory responses and apoptosis in bMECs induced by $K$. pneumoniae by decreasing bacterial adhesion and invasion and suppressing expression of inflammatory factors. We concluded that bacteriophages CM8-1 and SJT-2 were protective in K. pneumoniae-

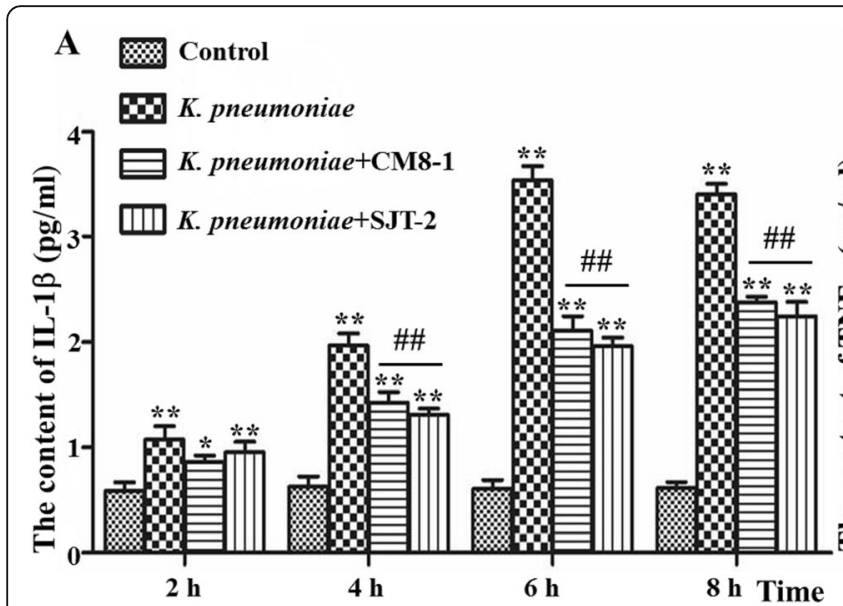

B

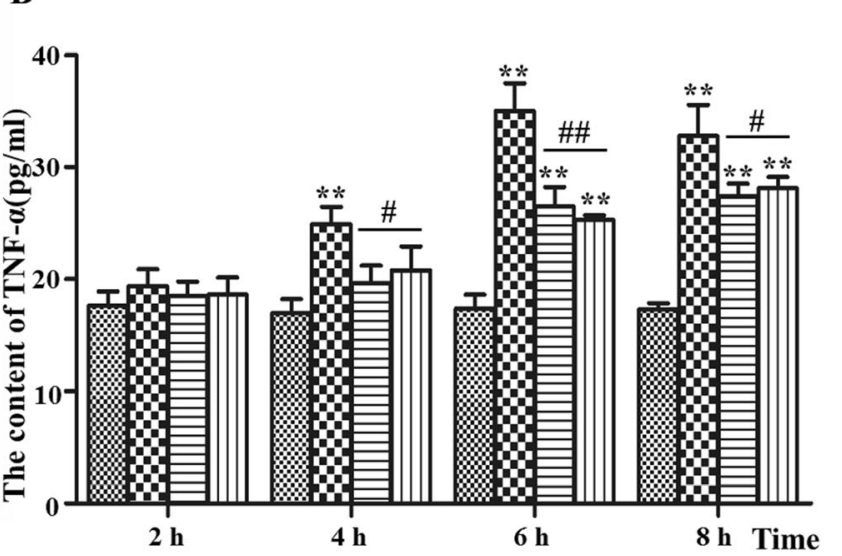

Fig. 5 Concentrations of $\mathrm{LL}-1 \beta$ and TNF-a proteins in the supernatant of Klebsiella pneumoniae-infected bovine mammary epithelial cells in presence of bacteriophages CM8-1 or SJT-2. a Content of IL-1 $\beta$ in the supernatant of K. pneumoniae infected bMECs, $\mathbf{b}$ Content of TNF-a in the supernatant of $K$. pneumoniae infected bMECs. Data presented as mean \pm SD for 3 independent experiments. Compared to the Control group: ${ }^{*} P<0.05,{ }^{* *} P<0.01$; compared to the K. pneumoniae group: ${ }^{\#} P<0.05,{ }^{\# \#} P<0.01$ 


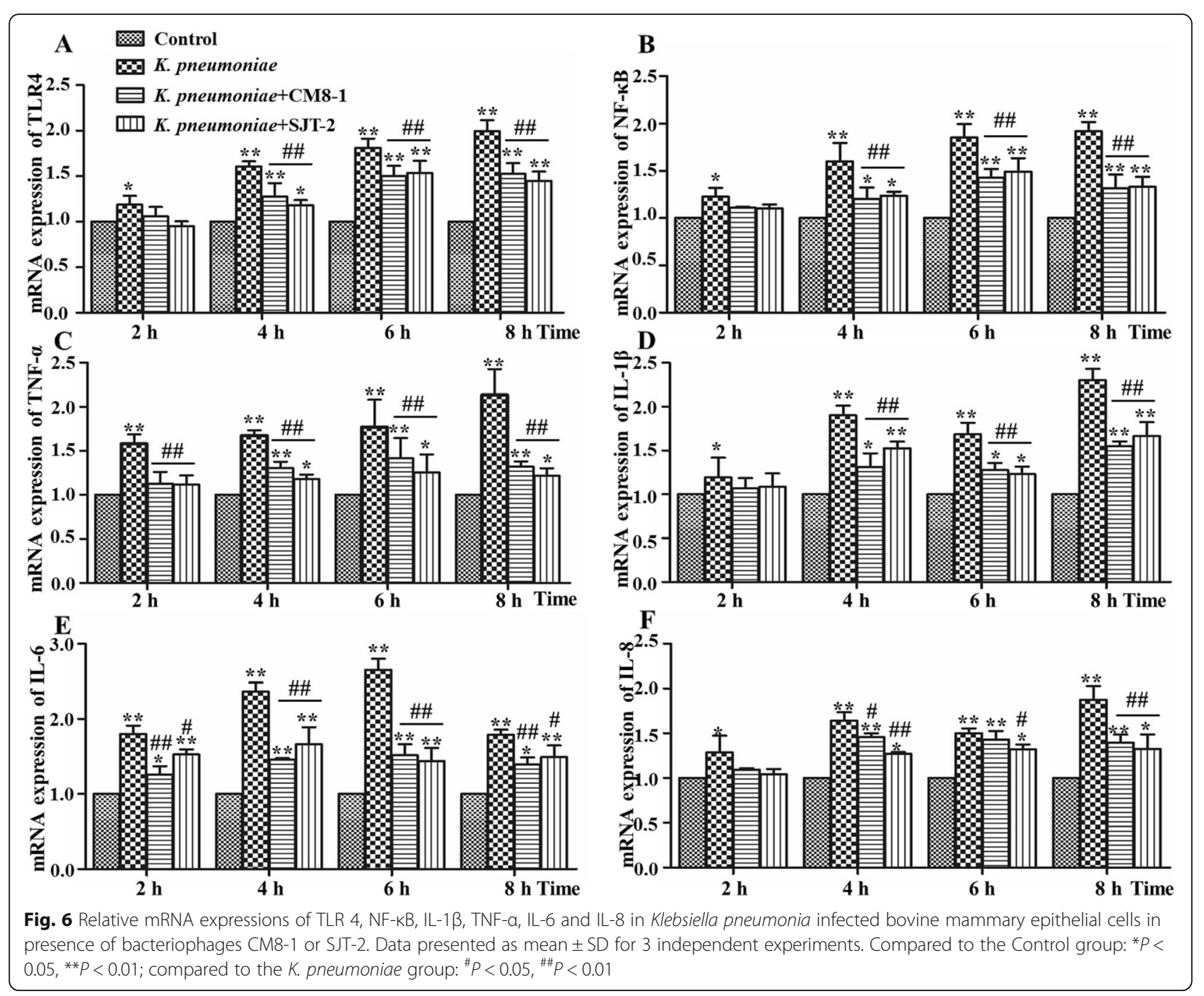

infected bMECs and therefore have potential therapeutic value against bovine mastitis caused by $K$. pneumoniae.

K. pneumoniae can infect a variety of cells and tissues, inducing inflammatory responses and cell damage [23-25]. In addition, it also infects bMECs in development of mastitis in dairy cows [26]. When bacteria infect cells, bacterial adhesion and invasion are critical determinants of virulence [27]; therefore, the absence of genes related to synthesis of adhesion proteins reduce adhesion rates and cell toxicity. Furthermore, pathogens with high rates of adhesion and invasion have potential to cause serious damage to cells. In this study, adhesion and invasion of $K$. pneumoniae to bMECs increased significantly with interval after infection, although this was mitigated by bacteriophages CM8-1 and SJT-2. Bacteriophages can specifically lyse pathogens and therefore reduce adhesion and invasion. In the current study, bacteriophages CM8-1 and SJT-2 reduced ability of K. pneumoniae to infect and bMECs by mitigating adhesion and invasion.
Lactate dehydrogenase (LDH) is an important marker of bacterial cytotoxicity [28, 29]. Infection of bMECs with gram-negative bacteria, including $K$. pneumoniae and E. coli, increases LDH release and is accompanied by substantial cell damage $[4,30]$. In this study, $\mathrm{LDH}$ significantly increased after bMECs were infected by $K$. pneumoniae, with increasing concentrations over time. Therefore, K. pneumoniae had toxic effects on bMECs, consistent with cell swelling and necrosis and decreasing numbers of bMECs.

A lack of toxic effects on host cells is characteristic of bacteriophages [19, 31]. Treatment of bMECs with either CM8-1 or SJT-2 bacteriophage did not increase release of $\mathrm{LDH}$ relative to the Control group, indicating that these bacteriophages were not toxic to bMECs. However, they can lyse and kill $K$. pneumoniae, reducing its virulence and mitigating damage to bMECs, manifested by less morphological damage and lower LDH concentrations. 


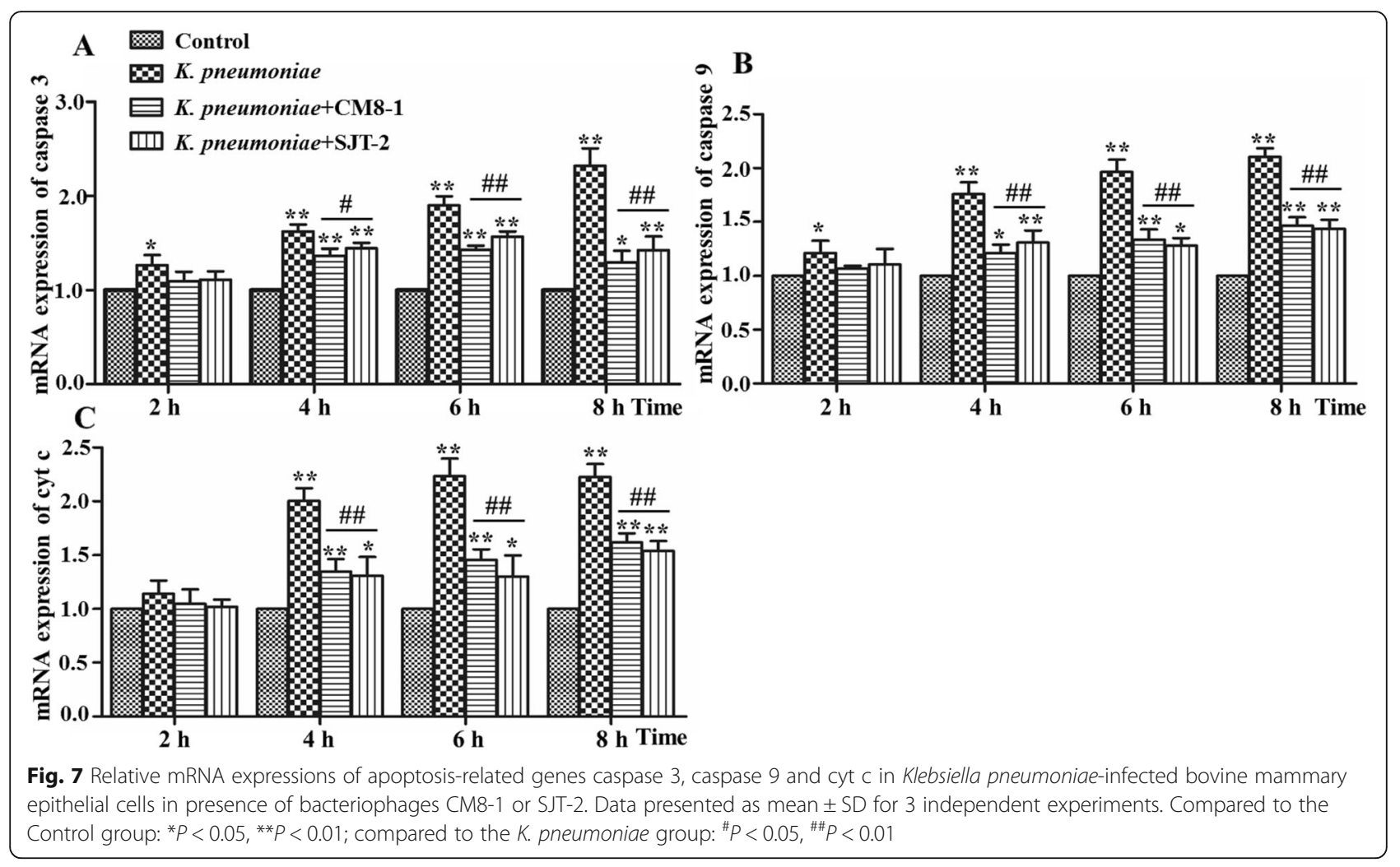

Infection of bMECs by pathogens in development of bovine mastitis is usually accompanied by a severe inflammatory response [32]. Various pathogenic bacteria, including K. pneumoniae, E. coli, S. aureus and S. agalactiae, cause inflammation by producing inflammatory factors $[4$, $33-35]$. In this study, concentrations of IL- $1 \beta$ and TNF- $\alpha$ in bMECs culture medium increased significantly after bMECs were infected with $K$. pneumoniae; furthermore, there was a positive association with duration of infection time, confirming K. pneumoniae-induced inflammation of bMECs. Gram negative bacteria such as K. pneumoniae and $E$. coli can activate TLR4 mediated NF- $\mathrm{kB}$ pathway to induce inflammation of bMECs $[4,11,36,37]$. In this study, after exposing bMECs to $K$. pneumoniae, mRNA levels of TLR4 and NF- $\mathrm{kB}$, in the pathway of regulating inflammatory response in bMECs, were significantly upregulated and positively associated with duration of infection. In addition, downstream genes in TLR4 and NF- $\mathrm{kB}$ pathways, namely mRNA expression levels of TNF- $\alpha$, IL$1 \beta$, IL-6 and IL- 8 in bMECs were also up-regulated, confirming that $K$. pneumoniae induced an inflammatory response in bMECs. However, bacteriophages CM8-1 and SJT-2 were able to lyse $K$. pneumoniae and mitigate the inflammatory response induced by $K$. pneumoniae, manifested by decreased concentrations of IL- $1 \beta$ and TNF- $\alpha$ in bMECs culture medium, as well as reduced mRNA expression levels of TLR4, NF- $k B$, TNF- $\alpha$, IL- $1 \beta$, IL-6 and IL-8.
In this study, K. pneumoniae induced apoptosis of bMECs. Mitochondria are involved in the common apoptotic pathway, which mainly depends on the caspase families and cyt-c for regulation [38-40]. In the current study, $K$. pneumoniae infection of bMECs presumably enhanced release of cyt-c from mitochondria, triggered the caspase- 9 and caspase- 3 cascade reaction and accelerated cell apoptosis. The mRNA expression of caspase-3, caspase-9 and cyt-c in bMECs significantly increased with duration of infection time, implying apoptosis was triggered by $K$. pneumoniae. Based on flow cytometry, the apoptosis rate of bMECs increased gradually after $K$. pneumoniae treatment, which further confirmed that $K$. pneumoniae induced apoptosis of bMECs. However, bacteriophages CM8-1 and SJT-2 decreased expression of caspase-3, caspase- 9 and cyt-c, as well as apoptosis rate of bMECs. Therefore, bacteriophages CM8-1 and SJT-2 mitigated apoptosis of bMECs induced by $K$. pneumoniae.

\section{Conclusions}

Bacteriophages CM8-1 and SJT-2 mitigated K. pneumoniae-induced inflammation in bovine mammary epithelial cells cultured in vitro. Therefore, the potential of these bacteriophages for treating mastitis in cows should be determined in clinical trials. 


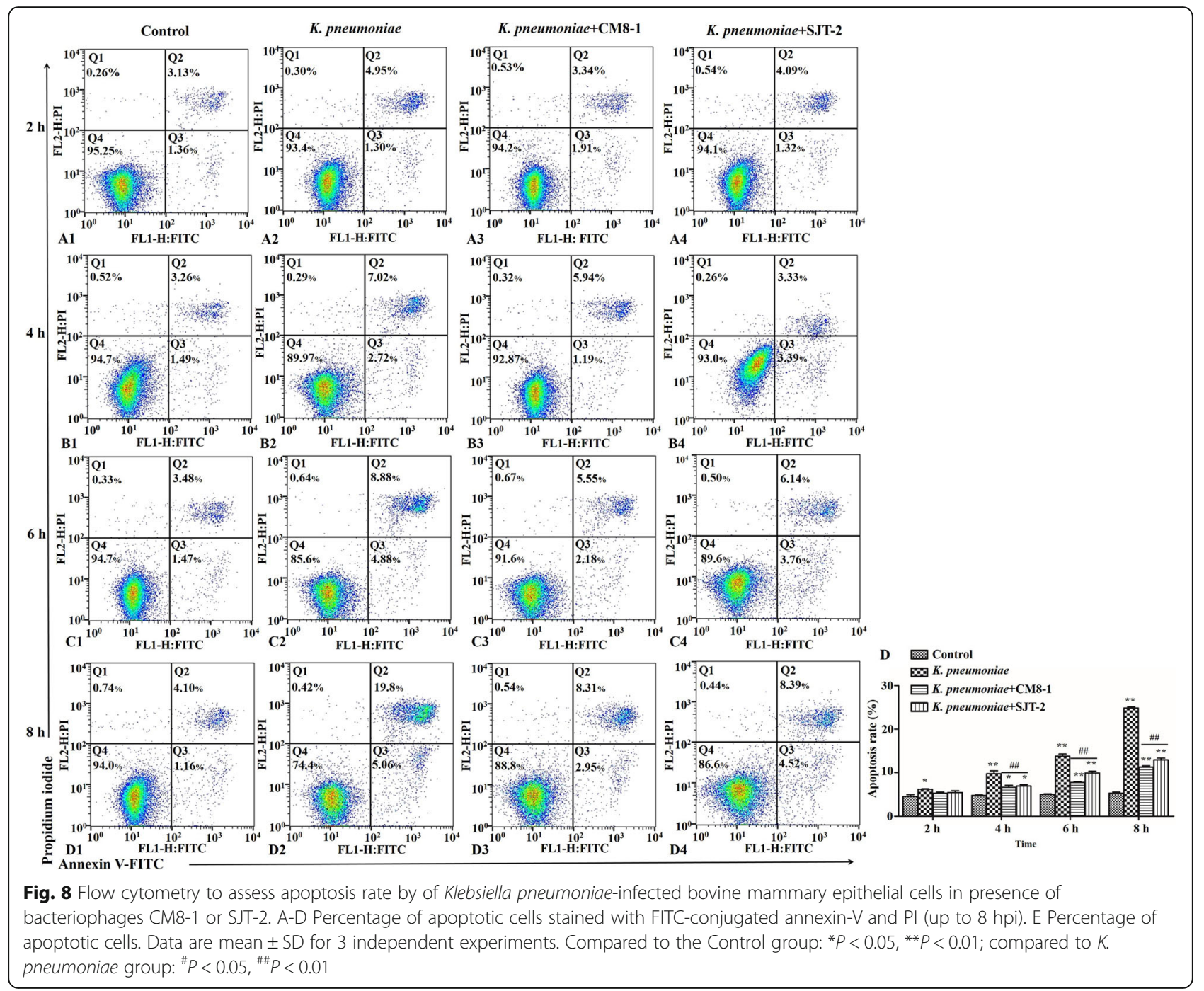

\section{Methods}

\section{Bacterial strains}

The bacterial strain used in this study, isolated from clinical mastitis in a dairy cow, was K. pneumoniae (CM-KP8) with K57 capsule serotype [4]. This isolate was stored at the mastitis diagnostic laboratory, College of Veterinary Medicine, China Agricultural University. Prior to each experiment, fresh bacterial suspensions were prepared from frozen stocks by culture on LB nutrient agar medium and incubated at $37{ }^{\circ} \mathrm{C}$ for $18 \mathrm{~h}$. Thereafter, bacteria were subcultured on brain heart infusion broth for $18 \mathrm{~h}$ to mid-log phase and bacterial concentration was determined by the plate counting method for the following experiments.

\section{Bacteriophages}

Bacteriophages CM8-1 and SJT-2 were isolated from dairy farm wastewater. Prior to each experiment, a bacterial solution in mid-log phase was mixed with bacteriophage stock solution and spread over a double-layer plate (96.6\% LB liquid medium and 3.4\% agar powder), with sodium magnesium (SM) buffer added after the bacteriophage had grown on the entire plate. Thereafter, this plate was placed on a shaker at $120 \mathrm{rpm} / \mathrm{min}$ for $2 \mathrm{~h}$ to liberate the bacteriophage from the plate and into the SM solution. The latter was collected and passed through a $0.22 \mu \mathrm{m}$ filter to obtain the bacteriophage stock solution. Thereafter, PEG8000 (10\%) was add into the bacteriophage suspension and left overnight at $4{ }^{\circ} \mathrm{C}$. Then, the bacteriophage suspension was centrifuged at $10,000 \times \mathrm{g}$ for $10 \mathrm{~min}$ to obtain bacteriophage precipitation. The above process was repeated twice to obtain pure bacteriophage. The bacteriophage precipitation was resuspended with DMEM for the following experiments.

\section{Cell culture and treatment}

Bovine mammary epithelial cells (bMECs), line MAC-T (Shanghai Jingma Biological Technology Co., Ltd. China), were cultured in Dulbecco's modified Eagle's 
medium (DMEM) supplemented with 10\% (v/v) Gibco $^{\circ}$ fetal bovine serum at $37{ }^{\circ} \mathrm{C}$ in a humidified atmosphere of $5 \% \mathrm{CO}_{2}$. Cells from 3 to 8 passages were used for experiments, with the same passages of cells used in each experiment. The bMECs were treated with or without $K$. pneumoniae (MOI, ratio of $K$. pneumoniae to bMECs was 10:1) and bacteriophages CM8-1 or SJT-2 (MOI, ratio of bacteriophage to $K$. pneumoniae was 1 : $10)$, to form the following groups: Control; $K$. pneumoniae infection group ( $K$. pneumoniae), K. pneumoniae plus bacteriophage CM8-1 group ( $K$. pneumoniae + CM8-1) and $K$. pneumoniae plus bacteriophage SJT-2 group (K. pneumoniae + SJT-2).

\section{Transmission electron microscopy (TEM)}

A suspension $(20 \mu \mathrm{L})$ of bacteriophages (titer $=10^{9}$ $\mathrm{PFU} / \mathrm{mL}$ ) was dropped on a copper mesh and precipitated for $2 \mathrm{~min}$ at room temperature, with excess liquid absorbed by filter paper. Bacteriophages were then stained with $2 \%$ uranium acetate for $1 \mathrm{~min}$, excess liquid absorbed, naturally dried for $15 \mathrm{~min}$ at room temperature and then observed under a transmission electron microscope (H-7650, Hitachi, Tokyo, Japan) at $80 \mathrm{kV}$.

\section{Adhesion and invasion}

Adhesion and invasion were measured as described [4]. The bMECs were inoculated into a 6-well cell culture plate and grown to $80 \%$ confluence, washed with phosphate buffer saline (PBS) and then DMEM supplemented with $1 \%(\mathrm{v} / \mathrm{v}) \mathrm{Gibco}^{\circ}$ Fetal Bovine Serum was added. At a multiplicity of infection (MOI, ratio of $K$. pneumoniae to cells) of 10:1, the bMECs were cultured at $37{ }^{\circ} \mathrm{C}$ in a humidified atmosphere of $5 \% \mathrm{CO}_{2}$ for $0.5 \mathrm{~h}$, and then with addition of bacteriophages CM8-1 or SJT-2 (MOI, ratio of bacteriophages to K. pneumoniae) of 1:10 for $0.5,1,1.5,2$ and $2.5 \mathrm{~h}$. After incubation, cells were washed with PBS (to remove non-adherent bacteria), and the cell suspension was 10-fold diluted and cultured on LB liquid medium plate for counting colony forming units. Meanwhile, after incubation, cells were washed with PBS and treated with $1 \mathrm{~mL}$ of DMEM containing kanamycin $(100 \mu \mathrm{g} / \mathrm{mL})$ and then cultured at $37{ }^{\circ} \mathrm{C}$ in a humidified atmosphere of $5 \% \mathrm{CO}_{2}$ for $2 \mathrm{~h}$. The culture medium was removed, cells were lysed with $0.5 \%$ TritonX-100 and the lysate diluted and cultured on LB liquid medium plate as described above. Colonies were counted and invasion rate of $K$. pneumoniae into bMECs was calculated.

\section{Lactate dehydrogenase (LDH) assay}

The bMECs were seeded in 96-well plates (density of $1 \times 10^{5}$ cells/well), grown to $80 \%$ confluence, then DMEM supplemented with $1 \%(\mathrm{v} / \mathrm{v})$ Gibco $^{\circ}$ Fetal Bovine
Serum was added. Cells were then treated with $K$. pneumoniae and bacteriophages CM8-1 or SJT-2, as described above. After culture for 1, 2, 4, 6 or $8 \mathrm{~h}$, supernatants were collected, centrifuged at $11,586 \times \mathrm{g}$ for 15 min at $4{ }^{\circ} \mathrm{C}$ and LDH release measured by cytotoxicity (LDH Assay Kit-WST ${ }^{\circ}$, Dojingdo Laboratories, Kumamoto, Japan), according to manufacturer's instructions. Absorbance of optical density was determined at $492 \mathrm{~nm}$ with a microplate reader (Bio-Rad, Hercules, CA, USA).

\section{Morphological observation of bMECs}

The bMECs were seeded in 6-well plates with glass slides and grown to $80 \%$ confluence. Cells were then treated with $K$. pneumoniae and bacteriophages CM81 or SJT-2, as described above. Cells were cultured at $37{ }^{\circ} \mathrm{C}$ in a humidified atmosphere of $5 \% \mathrm{CO}_{2}$ for 2,4 , 6 or $8 \mathrm{~h}$. Then, cells were collected, fixed in $4 \%$ paraformaldehyde for $30 \mathrm{~min}$, washed 3 times with PBS and dried naturally for $5 \mathrm{~min}$. Hematoxylin-eosin (HE) staining was performed according to manufacturer's instructions. An increasing alcohol gradient (75, 85, 95 and 100\%) was used to dehydrate cells, which were subsequently observed under a light microscope at $40 x$.

\section{Detection of cytokine concentrations}

Culture medium was collected, centrifuged at 11, $586 \times \mathrm{g}$ for $10 \mathrm{~min}$ at $4{ }^{\circ} \mathrm{C}$ and supernatant removed. Concentrations of inflammatory cytokines TNF- $\alpha$ and IL-1 $\beta$ in supernatant were measured using ELISA kits (Shanghai Zhenke Biotechnology Co., Ltd, Shanghai, China), used in accordance with manufacturer's instructions.

\section{Quantifying cytokine mRNA with real-time PCR}

The bMECs were treated with $K$. pneumoniae and bacteriophages CM8-1 or SJT-2, and cells collected for total RNA extraction. Trizol Reagent $(1 \mathrm{~mL})$ was pre-chilled on ice and added to cell samples for 5 min to lyse cells. Mixed liquid was centrifuged at $11,586 \times \mathrm{g}$ for $15 \mathrm{~min}$ at $4{ }^{\circ} \mathrm{C}$ and supernatant collected. Total mRNA of bMECs was extracted with mRNA extraction kit (TransGen Biotech Co., Ltd. Beijing, China), used according to manufacturer's instructions. Primers for GAPDH (housekeeping gene), TLR4, NF- $\kappa B$, TNF- $\alpha$, IL-1 $\beta$, IL-6, IL-8, caspase-3, caspase- 9 and cyt-c were designed using primer 5.0 software (Table 1). Relative expression levels of TLR4, NF- $\kappa B$, TNF- $\alpha$, IL-1 $\beta$, IL-6, IL-8, caspase-3, caspase-9 and cyt-c mRNA were determined using the Mx3000P ${ }^{\text {mix }}$ RT-PCR system (Stratagene, USA) realtime PCR RG-3000A and the SYBR Premix Ex Taq ${ }^{\mathrm{Tm}}$ (Perfect Real Time) Kit (Takara, Japan). 
Table 1 List of primers for real-time PCR

\begin{tabular}{|c|c|c|c|}
\hline Gene & Primer & Sequence $\left(5^{\prime}-3^{\prime}\right)$ & Size (bp) \\
\hline GAPDH & $\begin{array}{l}\text { Forward } \\
\text { Reverse }\end{array}$ & $\begin{array}{l}\text { TCACCAACTGGGACGACA } \\
\text { GCATACAGGGACAGCACA }\end{array}$ & 206 \\
\hline TLR4 & $\begin{array}{l}\text { Forward } \\
\text { Reverse }\end{array}$ & $\begin{array}{l}\text { GGACCCTTGCGTACAGGTTG } \\
\text { GGAAGCTGGAGAAGTTATGGC }\end{array}$ & 155 \\
\hline$N F-k B$ & $\begin{array}{l}\text { Forward } \\
\text { Reverse }\end{array}$ & $\begin{array}{l}\text { GACCAAGGAGATGGACCTGA } \\
\text { ACGATITTCAGGTTGGATGC }\end{array}$ & 150 \\
\hline TNF-a & $\begin{array}{l}\text { Forward } \\
\text { Reverse }\end{array}$ & $\begin{array}{l}\text { ATGTGTGTGGAGAGCGTCAA } \\
\text { GGGCCATACAGCTCCACAAA }\end{array}$ & 145 \\
\hline$I L-1 \beta$ & $\begin{array}{l}\text { Forward } \\
\text { Reverse }\end{array}$ & $\begin{array}{l}\text { ATGACTTCCAAGCTGGCTGTTG } \\
\text { TTGATAAATTTGGGGTGGAAAG }\end{array}$ & 114 \\
\hline IL-6 & $\begin{array}{l}\text { Forward } \\
\text { Reverse }\end{array}$ & $\begin{array}{l}\text { GCGCATCGGAGATGAATTGG } \\
\text { AGATGGTCACTGTCCAACCAC }\end{array}$ & 296 \\
\hline IL-8 & $\begin{array}{l}\text { Forward } \\
\text { Reverse }\end{array}$ & $\begin{array}{l}\text { AGTGCCTACGCACATGTCTTC } \\
\text { TGCGTCACACAGAAACTCGTC }\end{array}$ & 151 \\
\hline Caspase-3 & $\begin{array}{l}\text { Forward } \\
\text { Reverse }\end{array}$ & $\begin{array}{l}\text { GATGACATCGCCTGTCAGAA } \\
\text { AATTCTGTTGCCACCTTCG }\end{array}$ & 203 \\
\hline Caspase-9 & $\begin{array}{l}\text { Forward } \\
\text { Reverse }\end{array}$ & $\begin{array}{l}\text { GTCACGGCTITGATGGAGAT } \\
\text { CAGGCCTGGATGAAGAAGAG }\end{array}$ & 224 \\
\hline Cyt-c & $\begin{array}{l}\text { Forward } \\
\text { Reverse }\end{array}$ & $\begin{array}{l}\text { TGCTGGTGATGTTGAGAAGG } \\
\text { GTGTCCTCGTTCCAGGTGAT }\end{array}$ & 327 \\
\hline
\end{tabular}

${ }^{a}$ Annealing temperature for all primers was $60^{\circ} \mathrm{C}$

\section{Detection of apoptosis by flow cytometry}

After bMECs were treated with K. pneumoniae and bacteriophages CM8-1 and SJT-2, apoptosis was assessed with an Annexin V-FITC apoptosis detection kit (Beyotime Biotechnology Co., Ltd, Shanghai, China). Cell culture fluid and washing fluid were collected. Then, cells were harvested with trypsin without EDTA and washed with PBS. Cells were centrifuged at $965 \times \mathrm{g}$ for $10 \mathrm{~min}$, supernatant removed and cells re-suspended in $195 \mu \mathrm{L}$ Annexin V-FITC binding solution and then transferred to a sterile flow cytometry glass tube. Annexin V-FITC $(5 \mu \mathrm{L})$ was add to the cell suspension, followed by $10 \mu \mathrm{L}$ propidium iodide staining solution. After $20 \mathrm{~min}$ at room temperature in dark conditions, apoptotic cells were detected using flow cytometry.

\section{Statistical analyses}

Data were expressed as mean \pm standard deviation (SD), followed by post hoc Tukey's tests using SPSS 22.0 (SPSS Inc., Chicago, IL, USA). All measurements were replicated three times and $P<0.05$ was considered significant.

\section{Abbreviations}

K. pneumoniae: Klebsiella pneumoniae; LDH: Lactate dehydrogenase; bMECs: bovine mammary epithelial cells; MOI: Multiplicity of infection; TLR: Toll-like Receptor; SM: Sodium magnesium; DMEM: Dulbecco's modified Eagle's medium; HE: Hematoxylin-eosin; TEM: Transmission electron microscopy; PCR: Polymerase chain reaction

\section{Acknowledgements}

Not applicable.

\section{Authors' contributions}

$\mathrm{BH}, J \mathrm{G}$ and JPK conceived and designed the experiment. YS and WZ performed the research and wrote the manuscript, GL, PC and YL performed the correlation of the genes to inflammation and apoptosis and associated interpretation, TA, YS and WZ wrote the first draft of the manuscript, JG assisted in the result analysis and re-edited the manuscript. BH and JPK revised the manuscript. All authors read and approved the final manuscript.

\section{Funding}

This study was financially supported by Beijing Municipal Natural Science Foundation (No. 6192013), the National Natural Science Foundation of China (No. 31772813 and 31572587), the National Key R\&D Project (No. 2016YFD0501203), Hebei Key R\&D Project (19226607D) and the High-end Foreign Experts Recruitment Program (No. GDT20171100013). The above "Funding Organizations" provided financial support, and they had no role in the design of the study and collection, analysis, and interpretation of data and in writing the manuscript.

\section{Availability of data and materials}

The datasets used and/or analyzed during the current study are available from the corresponding author on reasonable request.

\section{Ethics approval and consent to participate}

The current work was carried out according to ethical guidelines of China Agricultural University (CAU), Beijing, and approved by China Agricultural University Animal Ethics Committee (protocol CAUAEC-2010-0603). There were no vulnerable populations involved and no endangered species used in the experiment

\section{Consent for publication}

Not applicable.

\section{Competing interests}

The authors declare that they have no competing interests.

\section{Author details}

${ }^{1}$ College of Veterinary Medicine, China Agricultural University, Yuan Ming Yuan West Road No. 2, Haidian District, 100193 Beijing, P. R. China. ${ }^{2}$ College of Life Sciences and Food Engineering, Hebei University of Engineering, 056038 Handan, Hebei, P.R. China. ${ }^{3}$ Center of Microbiology \& Biotechnology, Veterinary Research Institute, Peshawar, Pakistan. ${ }^{4}$ College of Veterinary Medicine, Shandong Agricultural University, 271018 Taian, China.

${ }^{5}$ Department of Production Animal Health, Faculty of Veterinary Medicine, University of Calgary, T2N 4N1 Calgary, AB, Canada.

Received: 3 July 2020 Accepted: 29 December 2020

Published online: 19 January 2021

\section{References}

1. Heikkilä AM, Liski E, Pyörälä S, Taponen S. Pathogen-specific production losses in bovine mastitis. J Dairy Sci. 2018;101:9493-504.

2. He W, Ma S, Lei L, He J, Li X, Tao J, Wang X, Song S, Wang Y, Wang Y, Shen J, Cai C, Wu C. Prevalence, etiology, and economic impact of clinical mastitis on large dairy farms in China. Vet Microbiol. 2020;242:108570.

3. Cheng J, Qu W, Barkema HW, Nobrega DB, Gao J, Liu G, De Buck J, Kastelic $J P$, Sun $H$, Han B. Antimicrobial resistance profiles of 5 common bovine mastitis pathogens in large Chinese dairy herds. J Dairy Sci. 2019;102: 2416-26.

4. Cheng J, Zhang J, Han B, Barkema HW, Cobo ER, Kastelic JP, Zhou M, Shi Y, Wang J, Yang R, Gao J. Klebsiella pneumoniae isolated from bovine mastitis is cytopathogenic for bovine mammary epithelial cells. J Dairy Sci. 2020;103: 3493-504.

5. Gao J, Barkema HW, Zhang L, Liu G, Deng Z, Cai L, Shan R, Zhang S, Zou J, Kastelic JP, Han B. Incidence of clinical mastitis and distribution of pathogens on large Chinese dairy farms. J Dairy Sci. 2017;100:4797-806.

6. Fuenzalida MJ, Ruegg PL. Negatively controlled, randomized clinical trial to evaluate intramammary treatment of nonsevere, gram-negative clinical mastitis. J Dairy Sci. 2019;102:5438-57. 
7. Xiu L, Fu YB, Deng Y, Shi XJ, Bian ZY, Ruhan A, Wang X. Deep sequencingbased analysis of gene expression in bovine mammary epithelial cells after Staphylococcus aureus, Escherichia coli, and Klebsiella pneumoniae infection. Genet Mol Res. 2015;14:16948-65.

8. Liu G, Liu Y, Ali T, Ferreri M, Gao J, Chen W, Yin J, Su J, Fanning S, Han B. Molecular and phenotypic characterization of Aerococcus viridans associated with subclinical bovine mastitis. PLoS One. 2015;10:e0125001.

9. Gao J, Li S, Zhang J, Zhou Y, Xu S, Barkema HW, Nobrega DB, Zhu C, Han B. Prevalence of potential virulence genes in Klebsiella spp. isolated from cows with clinical mastitis on large Chinese dairy farms. Foodborne Pathog Dis. 2019;16:856-63.

10. Lan J, Dou X, Li J, Yang Y, Xue C, Wang C, Gao N, Shan A. L-arginine ameliorates lipopolysaccharide-induced intestinal inflammation through inhibiting the TLR4/NF-KB and MAPK pathways and stimulating $\beta$-defensins expression in vivo and in vitro. J Agric Food Chem. 2020;68:2648-63.

11. Zhao C, Wang Y, Yuan X, Sun G, Shen B, Xu F, Fan G, Jin M, Li X, Liu G. Berberine inhibits lipopolysaccharide-induced expression of inflammatory cytokines by suppressing TLR4-mediated NF-KB and MAPK signaling pathways in rumen epithelial cells of Holstein calves. J Dairy Res. 2019;86: $171-6$.

12. Nyati KK, Masuda K, Zaman MM, Dubey PK, Millrine D, Chalise JP, Higa M, Li S, Standley D, Saito K, Hanieh H, Kishimoto T. TLR4-induced NF-KB and MAPK signaling regulate the IL-6 mRNA stabilizing protein Arid5a. Nucleic Acids Res. 2017:45:2687-703.

13. Pasparakis $M$, Vandenabeele $P$. Necroptosis and its role in inflammation. Nature. 2015;517:311-20.

14. Bergsbaken T, Fink SL, Cookson BT. Pyroptosis: host cell death and inflammation. Nat Rev Microbiol. 2009;7:99-109.

15. Bannerman DD, Paape M, Hare WR, Hope JC. Characterization of the bovine innate immune response to intramammary infection with Klebsiella pneumoniae. J Dairy Sci. 2004;87:2420-32.

16. Kieffer N, Poirel L, Nordmann P, Madec JY, Haenni M. Emergence of colistin resistance in Klebsiella pneumoniae from veterinary medicine. J Antimicrob Chemother. 2015;70:1265-7.

17. Saidani M, Messadi L, Soudani A, Daaloul-Jedidi M, Châtre P, Ben Chehida F, Mamlouk A, Mahjoub W, Madec J, Haenni M. Epidemiology, antimicrobial resistance, and extended spectrum beta-lactamase-producing enterobacteriaceae in clinical bovine mastitis in Tunisia. Microb Drug Resist. 2018;24:1242-8.

18. Díaz-Muñoz SL, Koskella B. Bacteria-phage interactions in natural environments. Adv Appl Microbiol. 2014;89:135-83.

19. Melo LDR, Oliveira H, Pires DP, Dabrowska K, Azeredo J. Phage therapy efficacy: a review of the last 10 years of preclinical studies. Crit Rev Microbiol. 2020:46:78-99.

20. Martín-Díaz J, Lucena F, Blanch AR, Jofre J. Review. Indicator bacteriophages in sludge, biosolids, sediments and soils. Environ Res. 2020;182:109133.

21. Lerondelle C, Poutrel B. Bacteriophage treatment trials on staphylococcal udder infection in lactating cows. Ann Rech Vet. 1980;11:421-6.

22. Gill JJ, Pacan JC, Carson ME, Leslie KE, Griffiths MW, Sabour PM. Efficacy and pharmacokinetics of bacteriophage therapy in treatment of subclinical Staphylococcus aureus mastitis in lactating dairy cattle. Antimicrob Agents Chemother. 2006;50:2912-8.

23. Malachowa N, Kobayashi SD, Porter AR, Freedman B, Hanley PW, Lovaglio J, Saturday GA, Gardner DJ, Scott DP, Griffin A, Cordova K, Long D, Rosenke R, Sturdevant DE, Bruno D, Martens C, Kreiswirth BN, Deleo FR. Vaccine protection against multidrug-resistant Klebsiella pneumoniae in a nonhuman primate model of severe lower respiratory tract infection. mBio. 2019;10: e02994-19.

24. Motta C, Salmeri M, Anfuso CD, Amodeo A, Scalia M, Toscano MA Giurdanella G, Alberqhina M, Lupoet G. Klebsiella pneumoniae induces an inflammatory response in an in vitro model of blood-retinal barrier. Infect Immun. 2014:82:851-63.

25. Vareille-Delarbre M, Miquel S, Garcin S, Bertran T, Balestrino D, Evrard B, Forestier C. Immunomodulatory effects of lactobacillus plantarum on inflammatory response induced by Klebsiella pneumoniae. Infect Immun. 2019:87:e00570-19.

26. Fuenzalida MJ, Ruegg PL. Molecular epidemiology of nonsevere clinical mastitis caused by Klebsiella pneumoniae occurring in cows on 2 Wisconsin dairy farms. J Dairy Sci. 2020;103:3479-92.

27. Confer AW, Ayalew S. The OmpA family of proteins: roles in bacterial pathogenesis and immunity. Vet Microbiol. 2013;163:207-22.
28. Chen W, Liu Y, Zhang L, Gu X, Liu G, Shahid M, Gao J, Ali T, Han B. Nocardia cyriacigeogica from bovine mastitis induced in vitro apoptosis of bovine mammary epithelial cells via activation of mitochondrial-caspase pathway. Front Cell Infect Microbiol. 2017;7:194.

29. Wei Z, Wang J, Wang Y, Wang C, Liu X, Han Z, Fu Y, Zhang N. Effects of neutrophil extracellular traps on bovine mammary epithelial cells in vitro. Front Immunol. 2019;10:1003.

30. Ali T, Ur Rahman S, Zhang L, Shahid M, Zhang S, Liu G, Gao J, Han B. ESBLproducing Escherichia coli from cows suffering mastitis in China contain clinical class 1 integrons with CTX-M linked to ISCR1. Front Microbiol. 2016; 7:1931.

31. Szafrański SP, Winkel A, Stiesch M. The use of bacteriophages to biocontrol oral biofilms. J Biotechnol. 2017;250:29-44.

32. Sordillo LM. Symposium review: Oxylipids and the regulation of bovine mammary inflammatory responses. J Dairy Sci. 2018:101:5629-41.

33. Alva-Murillo N, Ochoa-Zarzosa A, López-Meza JE. Sodium octanoate modulates the innate immune response of bovine mammary epithelial cells through the TLR2/P38/JNK/ERK1/2 pathway: Implications during Staphylococcus aureus internalization. Front Cell Infect Microbiol. 2017;7:78.

34. Caldeira MO, Bruckmaier RM, Wellnitz O. Meloxicam affects the inflammatory responses of bovine mammary epithelial cells. J Dairy Sci. 2019:102:10277-90.

35. Zhang $H$, Jiang $H$, Fan $Y$, Chen Z, Li M, Mao Y, Karrow NA, Loor JJ, Moore S, Yang Z. Transcriptomics and iTRAQ-proteomics analyses of bovine mammary tissue with Streptococcus agalactiae-induced mastitis. J Agric Food Chem. 2018:66:11188-96.

36. Ma N, Chang G, Huang J, Wang Y, Gao Q, Cheng X, Liu J, Shen X. Cis-9, trans-11-conjugated linoleic acid exerts an anti-inflammatory effect in bovine mammary epithelial cells after Escherichia coli stimulation through NF-KB signaling pathway. J Agric Food Chem. 2019;67:193-200.

37. Wachi S, Kanmani P, Tomosada Y, Kobayashi H, Yuri T, Egusa S, Shimazu T, Suda Y, Aso H, Sugawara M, Saito T, Mishima T, Villena J, Ketazawaet H. Lactobacillus delbrueckii TUA4408L and its extracellular polysaccharides attenuate enterotoxigenic Escherichia coli-induced inflammatory response in porcine intestinal epitheliocytes via Toll-like receptor-2 and 4. Mol Nutr Food Res. 2014;58:2080-93.

38. Li X, Fang F, Gao Y, Tang G, Xu W, Wang Y, Kong R, Tuyihong A, Wang Z. ROS induced by killer red. targeting mitochondria (mtKR) enhances apoptosis caused by radiation via Cyt c/Caspase-3 pathway. Oxid Med Cell Longev. 2019;2019:4528616.

39. Wang HW, Zhang Y, Tan PP, Jia LS, Chen Y, Zhou BH. Mitochondrial respiratory chain dysfunction mediated by ROS is a primary point of fluoride-induced damage in Hepa1-6 cells. Environ Pollut. 2019;255:113359.

40. Yang Y, Yu Y, Wang J, Li Y, Li Y, Wei J, Zheng T, Jin M, Sun Z. Silica nanoparticles induced intrinsic apoptosis in neuroblastoma SH-SY5Y cells via CytC/Apaf-1 pathway. Environ Toxicol Pharmacol. 2017:52:161-9.

\section{Publisher's Note}

Springer Nature remains neutral with regard to jurisdictional claims in published maps and institutional affiliations.

Ready to submit your research? Choose BMC and benefit from:

- fast, convenient online submission

- thorough peer review by experienced researchers in your field

- rapid publication on acceptance

- support for research data, including large and complex data types

- gold Open Access which fosters wider collaboration and increased citations

- maximum visibility for your research: over $100 \mathrm{M}$ website views per year

At $\mathrm{BMC}$, research is always in progress.

Learn more biomedcentral.com/submissions 